\title{
Chemoselective Hydrogenation of Nitroarenes Using an Air-Stable Base-Metal Catalyst
}

\author{
Viktoriia Zubar, Abhishek Dewanji, and Magnus Rueping*
}

Cite This: https://doi.org/10.1021/acs.orglett.1c00659

Read Online

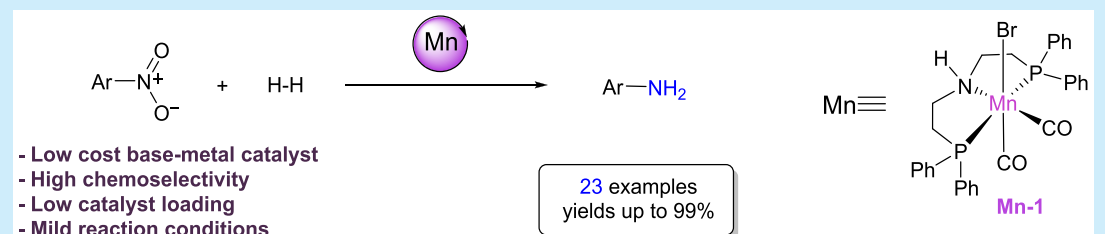

ABSTRACT: The reduction of nitroarenes to anilines as well as azobenzenes to hydrazobenzenes using a single base-metal catalyst is reported. The hydrogenation reactions are performed with an air-and moisture-stable manganese catalyst and proceed under relatively mild reaction conditions. The transformation tolerates a broad range of functional groups, affording aniline derivatives and hydrazobenzenes in high yields. Mechanistic studies suggest that the reaction proceeds via a bifunctional activation involving metalligand cooperative catalysis.

$\mathrm{T}$ he reduction of nitroarenes to anilines represents one of the most significant reactions in organic chemistry. In this context, various procedures were developed to obtain anilines via the hydrogenation of nitroarenes. ${ }^{1-3}$ This straightforward approach features minimum waste generation because it gives water as the sole byproduct. ${ }^{4}$ The hydrogenation of nitroarenes also has great importance in industry due to the high demand for anilines for pharmaceuticals, dyes, agrochemical production, and polyurethanes synthesis. One of the commonly used reactions converting nitroarenes into anilines is Bechamp reduction. $^{5}$ Despite a high functional group tolerance, this process exhibits considerable drawbacks, as it requires the use of corrosive hydrochloric acid and superstoichiometric amounts of iron or iron salts, leading to significant amounts of waste. Because of the high importance of substituted anilines, more economically beneficial methods are required. At present, the most commonly applied procedure is the catalytic hydrogenation of nitroarenes utilizing expensive $\mathrm{Pd} / \mathrm{C}$ or pyrophoric Raney-Ni catalysts, which often suffer from low chemoselectivity. The desired chemoselectivity can be achieved by the modification of the standard catalysts. The application of modifiers usually decreases the reactivity as a result of the coverage of the active site and also involves laborious, complex, and not always reproducible preparation. ${ }^{1}$ Most of the recent reports for the catalytic hydrogenation of nitroarenes focus on the development and modification of heterogeneous catalysts. ${ }^{1-3}$ In contrast, only a few methods for the homogeneous reduction of nitroarenes are known. Given that homogeneous metal catalysts can be readily modified and adjusted by the application of different ligands or metals, higher chemoselectivity can often be realized. This is important for the synthesis of specific pharmaceuticals, which require high selectivity and low toxicity of the catalyst. For this reason a range of protocols were developed using homogeneous catalysts based on noble metals including $\mathrm{Au}^{6}{ }^{6} \mathrm{Ir}^{7} \mathrm{Pd},{ }^{6,8,9}$ $\mathrm{Pt},{ }^{8,10} \mathrm{Rh},{ }^{7,11}$ and $\mathrm{Ru} .{ }^{8,12-14}$ Nevertheless, the replacement of noble-metal catalysts by earth-abundant alternatives is highly desirable in the context of sustainable chemistry. The first attempts to apply base-metal catalysts in the hydrogenation of nitroarenes to anilines were made by Knifton. ${ }^{12} \mathrm{Fe}$ $(\mathrm{CO})_{3}\left(\mathrm{PPh}_{3}\right)_{2}$ and $\mathrm{Fe}(\mathrm{CO})_{3}\left(\mathrm{AsPh}_{3}\right)_{2}$ were applied in low catalytic loading, leading to the selective formation of aniline under moderately mild conditions. Apart from this, Chaudhari et al. performed the hydrogenation of nitroarenes in aqueous/ organic biphasic medium using an $\mathrm{Fe} / \mathrm{EDTANa}_{2}$ system. ${ }^{15}$ The presence of a biphasic system allows a better separation of the product from the catalyst but also slows down the reaction. Good chemoselectivities were observed despite the use of a relatively high reaction temperature of $150{ }^{\circ} \mathrm{C}$. In 2013 , Beller and coworkers reported an iron-based complex for the catalytic hydrogenation of nitroarenes. ${ }^{16}$ The developed system operates under relatively mild reaction conditions and tolerates various functional groups. Here, up to 2 equiv of a strong acid, such as trifluoroacetic acid, was added to achieve significant catalyst activity.

Received: February 24, 2021 
Our interest in manganese catalysis ${ }^{17}$ and the lack of reports regarding its application in the hydrogenation of nitroarenes motivated us to address this issue. Recently, the application of manganese, as the third most abundant metal in the Earth's crust, for the catalytic hydrogenation of organic molecules has considerably increased. ${ }^{18-31}$ To the best of our knowledge, no manganese-catalyzed reduction of nitroarenes to anilines has been previously reported, although manganese catalysis has been shown to be rather chemoselective. ${ }^{1-3}$ Hence we decided to explore a manganese-catalyzed reaction.

We started our investigation with the application of $\mathbf{M n - 1}$ catalyst, which can be easily prepared from a commercially available ligand and metal precursor and is able to activate molecular hydrogen, thereby being a powerful, inexpensive, and environmentally friendly reducing catalyst.

Nitrobenzene (1a) was chosen as model substrate to determine the optimal reaction conditions. Initially, we attempted to hydrogenate nitrobenzene using $5 \mathrm{~mol} \%$ of $\mathrm{Mn}-1$ and $12.5 \mathrm{~mol} \%$ of $\mathrm{KO}^{t} \mathrm{Bu}$ in toluene at $130{ }^{\circ} \mathrm{C}$, applying 50 bar of $\mathrm{H}_{2}$ for $24 \mathrm{~h}$. We were pleased to see that the Mn-1 catalyst was active towards the reduction of nitrobenzene, producing the desired aniline (2a) in 59\% GC yield (Table 1,

Table 1. Optimization of the Reaction Conditions ${ }^{a}$<smiles>O=[N+]([O-])c1ccccc1</smiles>

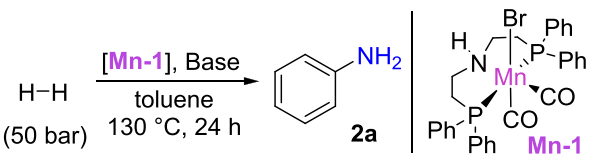

entry

1

2

3

4

5

6

7

$8^{c}$

$9^{d}$

$10^{d}$

$11^{d, e}$

$$
\text { solvent }
$$

toluene

1,4-dioxane

TAA

toluene

toluene

toluene

toluene

toluene

toluene

toluene

toluene base

$\mathrm{KO}^{t} \mathrm{Bu}$
$\mathrm{KO}^{t} \mathrm{Bu}$
$\mathrm{KO}^{t} \mathrm{Bu}$
$\mathrm{Cs}_{2} \mathrm{CO}_{3}$
$\mathrm{CsOH} \cdot \mathrm{H}_{2}$
$\mathrm{~K}_{2} \mathrm{CO}_{3}$
$\mathrm{KH}$
$\mathrm{K}_{2} \mathrm{CO}_{3}$
$\mathrm{~K}_{2} \mathrm{CO}_{3}$
$\mathrm{~K}_{2} \mathrm{CO}_{3}$
yield $(\%)^{b}$

59

44

21

35

52

87

27

$>99$

$>99$

$<5$

$\mathrm{nr}$

${ }^{a}$ Reaction conditions: nitrobenzene ( $\left.0.25 \mathrm{mmol}\right), \mathbf{M n}-1$ (5 mol \%), base $(12.5 \mathrm{~mol} \%)$ in $1 \mathrm{~mL}$ of toluene at $130{ }^{\circ} \mathrm{C}$ under 50 bar of $\mathrm{H}_{2}$ for $24 \mathrm{~h} .{ }^{b}$ Determined by the GC analysis using dodecane as an internal standard. ${ }^{c} 140{ }^{\circ} \mathrm{C} .{ }^{d} 80$ bar of $\mathrm{H}_{2} .{ }^{e}$ Without the catalyst. TAA, $t$-amyl alcohol.

entry 1). In the next step, other solvents were tested. The use of polar aprotic 1,4-dioxane resulted in a $44 \%$ yield of $\mathbf{2 a}$ (Table 1, entry 2), whereas the application of $t$-amyl alcohol led to a $21 \%$ yield (Table 1 , entry 3 ). Hence, with toluene as the solvent, we decided to investigate different bases. When $\mathrm{Cs}_{2} \mathrm{CO}_{3}$ was used for the activation of the catalyst, the yield dropped to $35 \%$, whereas $\mathrm{CsOH} \cdot \mathrm{H}_{2} \mathrm{O}$ showed similar reactivity to $\mathrm{KO}^{t} \mathrm{Bu}$, affording $2 \mathrm{a}$ in $52 \%$ yield (Table 1, entries 4 and 5). To our delight, the use of cheap and readily available $\mathrm{K}_{2} \mathrm{CO}_{3}$ in the reaction led to the formation of aniline in $87 \%$ yield (Table 1 , entry 6). Lastly, $\mathrm{KH}$ was tested; however, it provided an unsatisfactory result with a $27 \%$ yield of the desired product (Table 1, entry 7). Next, we increased the reaction temperature and pressure of $\mathrm{H}_{2}$ to $80 \mathrm{bar}$, which allowed us to reach a $>99 \%$ yield of the aniline in both cases (Table 1, entries 8 and 9). As expected, the reaction did not

take place in the absence of the catalyst or base (Table 1, entries 10 and 11).

With the optimized reaction conditions in hand, we started to explore the substrate scope for the hydrogenation of nitroarenes (Scheme 1). A range of alkyl-substituted nitroarenes were well tolerated and provided the corresponding anilines $\mathbf{2 b}-\mathbf{2 e}$ in excellent yields of up to $97 \%$. It should be noted that halogenated substrates were well tolerated, affording high yields of the desired aniline derivatives $\mathbf{2} \mathbf{f}-\mathbf{2} \mathbf{i}$. Remarkably, no protodehalogenation of the $\mathrm{C}-\mathrm{Hal}$ bond

Scheme 1. Selective Hydrogenation of Nitroarenes Catalyzed by $\mathrm{Mn}-\mathbf{1}^{a}$

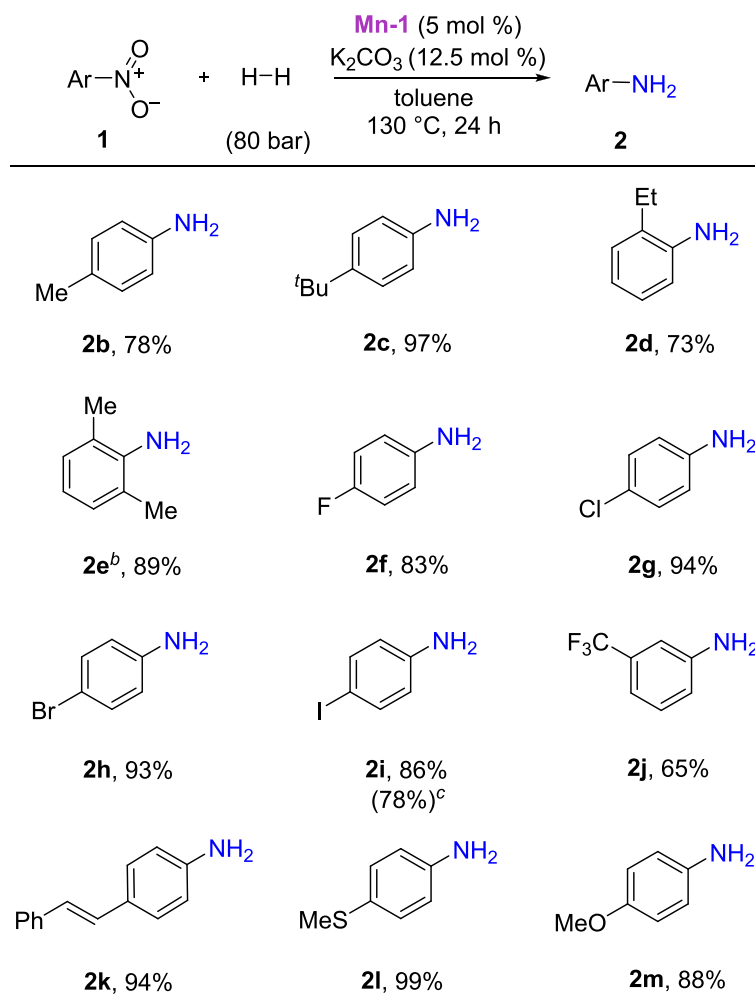<smiles>Nc1ccc(OBr)cc1</smiles><smiles>Nc1ccc2c(c1)OCO2</smiles>

$20^{b}, 96 \%$<smiles>Nc1ccc(C(=O)NCc2ccccc2)cc1</smiles>

2 r, $85 \%$<smiles>Nc1ccccc1S(=O)(=O)Nc1ccccc1</smiles>

$2 u, 78 \%$<smiles>COC(=O)c1ccc(N)cc1</smiles>

2 p, $79 \%$<smiles>Nc1ccc(N)cc1</smiles>

2s, $93 \%$

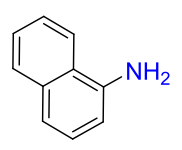

$2 \mathbf{v}^{b, d}, 75 \%$
${ }^{a}$ Reaction conditions: nitroarene (0.25 mmol), Mn-1 (5 mol \%), $\mathrm{K}_{2} \mathrm{CO}_{3}(12.5 \mathrm{~mol} \%)$ in $1 \mathrm{~mL}$ of toluene at $130{ }^{\circ} \mathrm{C}$ under 80 bar of $\mathrm{H}_{2}$. Yields after isolation. ${ }^{b} \mathbf{M n}-\mathbf{1}(10 \mathrm{~mol} \%), \mathrm{K}_{2} \mathrm{CO}_{3}(25 \mathrm{~mol} \%) .{ }^{c} \mathbf{1 i}$ $(1 \mathrm{~g})$, Mn-1 $(4 \mathrm{~mol} \%), \mathrm{K}_{2} \mathrm{CO}_{3}(10 \mathrm{~mol} \%)$ in $5 \mathrm{~mL}$ of toluene. ${ }^{d} 48 \mathrm{~h}$. 
took place, and a trifluoromethyl group in the meta position of the aromatic ring was also tolerated $(2 \mathbf{j})$. The developed system is able to chemoselectively reduce the nitro group in the presence of a double bond (2k), ester group (2p, 2q), amide functionality (2r), and compounds containing a sulfonamide residue $(\mathbf{2 u})$. Other functional groups such as ether and thioether and the amino group were well tolerated, and the desired anilines (21-2o and $\mathbf{2 s}, \mathbf{2 t}$ ) could be isolated in very high yields of up to $99 \%$. Finally, 1-nitronaphthalene (1v) was successfully applied, providing naphthalen-1-amine $(2 \mathbf{v})$ in $75 \%$ yield. Unfortunately, under the general reaction conditions, nitriles, certain ketones, alkynes, and olefins are partially reduced.

Additionally, a gram-scale synthesis of 4-iodoaniline could also be performed using the optimized reaction conditions. The product $2 \mathbf{i}$ was formed in $78 \%$ yield (Scheme 1 ), implying the feasibility of the described protocol. To show the general applicability of the developed method, we decided to perform the hydrogenation of $\mathbf{1 w}$, an intermediate in the synthesis of vortioxetine, an antidepressant used to treat major depressive disorder. A newly developed synthetic route includes the nucleophilic substitution of 2,4-dimethylbenzenethiol with 1chloro-2-nitrobenzene to afford the desired intermediate $\mathbf{1 w} .^{32}$ Under the optimized reaction conditions, the formed nitrophenylsulfane derivative $\mathbf{1} \mathbf{w}$ undergoes catalytic hydrogenation, leading to the desired thioaniline derivative $2 w$ in $74 \%$ yield (Scheme 2). It is important to note that the transition metals

\section{Scheme 2. Synthesis of Vortioxetine Intermediate}

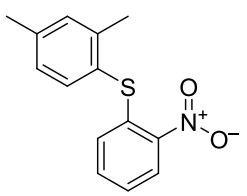

$1 \mathrm{w}, 200 \mathrm{mg}$

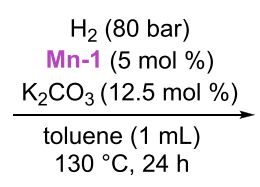

$130^{\circ} \mathrm{C}, 24 \mathrm{~h}$

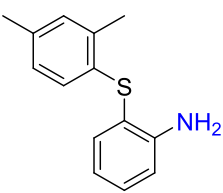

$2 w, 74 \%$ are often inhibited by thio- and amino groups and result in reduced activity. Furthermore, several $\mathrm{M}(0)$ species generated in late transition-metal-catalyzed reactions undergo $\mathrm{C}-\mathrm{S}$-type oxidative additions that can be prevented by the use of manganese catalysts, such as $\mathbf{M n}-\mathbf{1}$. The reaction of $\mathbf{2 w}$ with 2chloro- $\mathrm{N}$-(2-chloroethyl)ethanamine hydrochloride then provides the desired vortioxetine.

There are two commonly studied pathways for the hydrogenation of nitroarenes to anilines. The first one is a direct pathway where the reduction proceeds via the formation of nitrosoarene and hydroxylamine intermediates. The second one occurs when an azoxy compound is formed by the condensation of nitrosoarene and hydroxylamine and later undergoes reduction to azo and hydrazo compounds (Scheme 3). To investigate the reaction mechanism of the studied catalytic system, possible intermediates were submitted to the standard reaction conditions. N-Phenylhydroxylamine (3), azobenzene (4), and 1,2-diphenylhydrazine (5) were tested (Scheme 4a). The reduction of $N$-phenylhydroxylamine led to the formation of $49 \%$ of aniline, whereas azobenzene and 1,2diphenylhydrazine provided only 7 and $10 \%$ of aniline, respectively. These results suggested that the nitroarenes undergo direct hydrogenation in the presence of the developed catalytic system. In the case of the formation of the unwanted azo and hydrazo compounds, Mn-1 can partially transform them into the desired anilines. It should be noted that we did
Scheme 3. Possible Pathways for the Hydrogenation of Nitroarenes

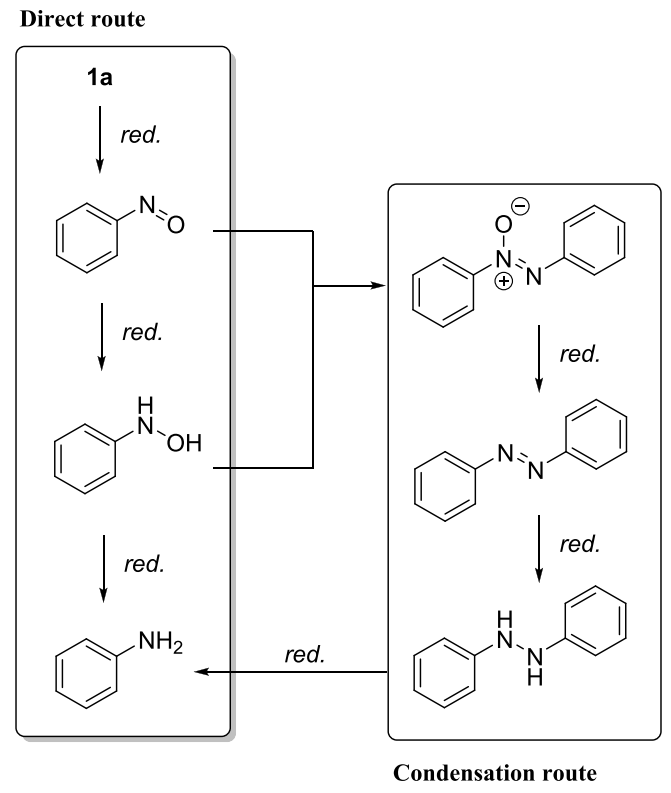

Scheme 4. Mechanistic Studies

a) Hydrogenation of Possible Intermediates
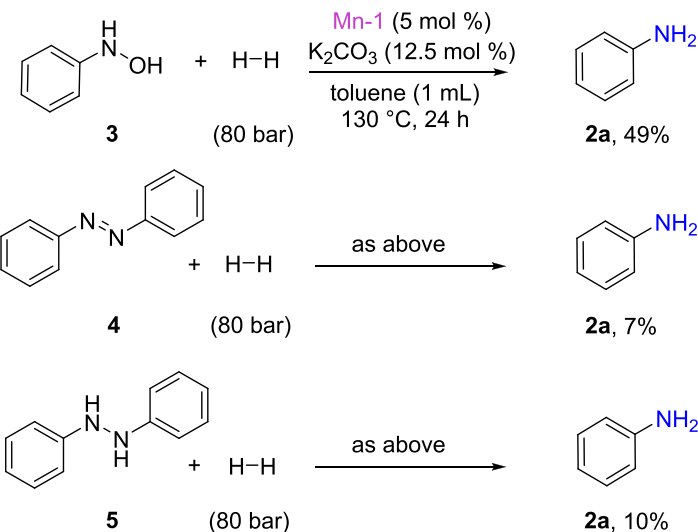

b) Metal-Ligand Cooperation

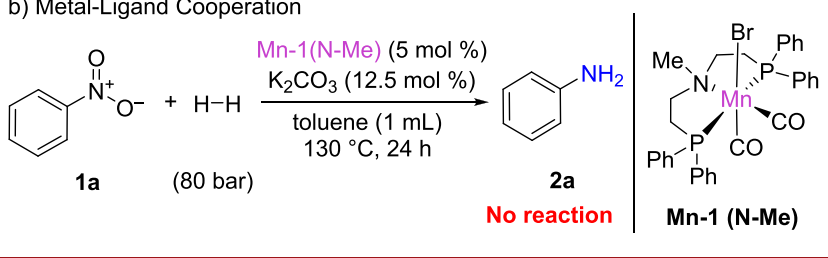

not observe the accumulation of intermediates such as hydroxylamine or azo, hydrazo, and azoxy compounds. Furthermore, we did not observe the formation of nanoparticles, as the pincer complexes are rather stable under the applied conditions. (See the SI for details.)

To prove whether the described reaction proceeds via metal-ligand cooperativity, ${ }^{33}$ we performed the hydrogenation reaction using the corresponding manganese $\mathbf{N}$-Me derivative of Mn-1 (Scheme 4b). As expected, the methylated complex Mn-1 (N-Me) appeared to be inactive in the hydrogenation of nitrobenzene under the optimized reaction conditions, indicating that the presence of the $\mathrm{N}-\mathrm{H}$ is critical for the reaction to proceed. 
While performing our mechanistic studies, we observed the formation of a significant amount of hydrazobenzene when azobenzene was used as starting material. Taking this observation into account, we decided to optimize the reaction conditions for hydrazobenzenes synthesis due to the high importance of hydrazobenzenes in the synthesis of dyes and pharmaceuticals. ${ }^{34}$ The conditions appeared to be very close to those applied for nitroarene hydrogenation. The catalytic hydrogenation of azobenzene to hydrazobenzene was previously achieved using rare and expensive transition metals like $\mathrm{Pd},{ }^{35} \mathrm{Pt}^{36}$ and $\mathrm{Ru}^{39}$

We were pleasantly surprised that our Mn-1 catalyst was able to convert azobenzene to hydrazobenzene selectively, producing anilines as minor byproducts. Thus we decided to explore the substrate scope (Scheme 5). Substrates with

Scheme 5. Selective Hydrogenation of Azobenzenes Catalyzed by $\mathrm{Mn}-1^{a}$

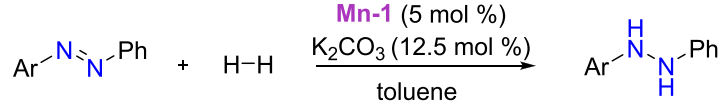

$$
\begin{aligned}
& 4 \quad \text { (80 bar) } \quad 135{ }^{\circ} \mathrm{C}, 24 \mathrm{~h} \quad 5
\end{aligned}
$$

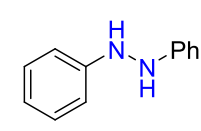

${ }^{a}$ Reaction conditions: azobenzene $(0.25 \mathrm{mmol}), \mathbf{M n}-1$ ( $\left.5 \mathrm{~mol} \%\right)$, $\mathrm{K}_{2} \mathrm{CO}_{3}(12.5 \mathrm{~mol} \%)$ in $1 \mathrm{~mL}$ of toluene at $135{ }^{\circ} \mathrm{C}$ under 80 bar of $\mathrm{H}_{2}$. Yields after isolation. ${ }^{b} \mathrm{Mn}-\mathbf{1}(7.5 \mathrm{~mol} \%), \mathrm{K}_{2} \mathrm{CO}_{3}(18.75 \mathrm{~mol} \%)$.

electron-donating and electron-withdrawing substituents were tolerated, although in some cases, a higher catalyst loading of $7.5 \mathrm{~mol} \%$ was required for the successful outcome of the reaction.

In conclusion, a manganese-catalyzed protocol for the hydrogenation of nitroarenes was developed using molecular hydrogen as a reducing agent. The applied catalyst Mn-1 can be synthesized from a commercially available manganese precursor and an air-stable and readily available PhPNP pincer ligand, highlighting the practicability of the developed protocol. The reaction proceeds under relatively mild conditions and provides the desired aniline derivatives in excellent yields. The newly developed manganese catalysis shows good reactivity and chemoselectivity and tolerates a variety of functional groups, leading to a practical protocol for the synthesis of anilines. Additionally, the hydrogenation of azobenzenes to hydrazobenzenes can be achieved, highlighting the high versatility of the developed catalytic system. The performed mechanistic studies suggested that the reaction takes place via metal-ligand cooperative catalysis and proceeds via a direct pathway to afford the desired anilines.

\section{ASSOCIATED CONTENT}

\section{sI Supporting Information}

The Supporting Information is available free of charge at https://pubs.acs.org/doi/10.1021/acs.orglett.1c00659.

Detailed experimental procedures, characterization, and copies of ${ }^{1} \mathrm{H}$ NMR and ${ }^{13} \mathrm{C}$ NMR spectra of all products and synthesized starting materials (PDF)

\section{AUTHOR INFORMATION}

\section{Corresponding Author}

Magnus Rueping - KAUST Catalysis Center (KCC), KAUST, Thuwal 23955-6900, Saudi Arabia; (1) orcid.org/ 0000-0003-4580-5227; Email: magnus.rueping@

kaust.edu.sa, magnus.rueping@rwth-aachen.de

Authors

Viktoriia Zubar - Institute of Organic Chemistry, RWTH Aachen University, 52074 Aachen, Germany

Abhishek Dewanji - Institute of Organic Chemistry, RWTH Aachen University, 52074 Aachen, Germany

Complete contact information is available at:

https://pubs.acs.org/10.1021/acs.orglett.1c00659

Notes

The authors declare no competing financial interest.

\section{ACKNOWLEDGMENTS}

We thank Dr. Jan Sklyaruk for his support in preparing the revision.

\section{REFERENCES}

(1) Blaser, H.-U.; Steiner, H.; Studer, M. Selective Catalytic Hydrogenation of Functionalized Nitroarenes: An Update. ChemCatChem 2009, 1, 210-221.

(2) Formenti, D.; Ferretti, F.; Scharnagl, F. K.; Beller, M. Reduction of Nitro Compounds Using 3d-Non-Noble Metal Catalysts. Chem. Rev. 2019, 119, 2611-2680.

(3) Orlandi, M.; Brenna, D.; Harms, R.; Jost, S.; Benaglia, M. Recent Developments in the Reduction of Aromatic and Aliphatic Nitro Compounds to Amines. Org. Process Res. Dev. 2018, 22, 430-445.

(4) Downing, R. S.; Kunkeler, P. J.; van Bekkum, H. Catalytic syntheses of aromatic amines. Catal. Today 1997, 37, 121-136.

(5) Béchamp, A. De l'action des protosels de fer sur la nitronaphtaline et la nitrobenzine. nouvelle méthode de formation des bases organiques artificielles de Zinin. Annales de Chimie et de Physique 1854, 42, 186-196.

(6) Corma, A.; González-Arellano, C.; Iglesias, M.; Sánchez, F. Gold complexes as catalysts: Chemoselective hydrogenation of nitroarenes. Appl. Catal., A 2009, 356, 99-102.

(7) Harsy, S. G. Homogeneous hydrogenation of nitroaliphatic compounds catalyzed by group VIII transition metal phosphine complexes. Tetrahedron 1990, 46, 7403-7412.

(8) Yu, Z.; Liao, S.; Xu, Y.; Yang, B.; Yu, D. Hydrogenation of nitroaromatics by polymer-anchored bimetallic palladium-ruthenium and palladium-platinum catalysts under mild conditions. J. Mol. Catal. A: Chem. 1997, 120, 247-255.

(9) Xu, S.; Xi, X.; Shi, J.; Cao, S. A homogeneous catalyst made of poly(4-vinylpyridine-co-N-vinylpyrrolidone)- $\mathrm{Pd}(0)$ complex for hydrogenation of aromatic nitro compounds. J. Mol. Catal. A: Chem. 2000, 160, 287-292.

(10) Zakhariev, A.; Ivanova, V.; Khidekel, M. L.; Chepaikin, E. G.; Shopov, D. Hydrogenation of aromatic nitro compounds in the presence of the platinum(II) complex of 1-phenylazo-2-naphthol in DMF. React. Kinet. Catal. Lett. 1978, 8, 195-201. 
(11) Chepaikin, E. G.; Khidekel', M. L.; Ivanova, V. V.; Zakhariev, A. I.; Shopov, D. M. Homogeneous catalytic hydrogenation of aromatic nitrocompounds by complexes of the platinum group metal with dyes. The reaction of nitrobenzene with a complex of rhodium with the anion-radical of potassium indigodisulfonate. J. Mol. Catal. 1980, 10, $115-119$.

(12) Knifton, J. F. Homogeneous catalyzed reduction of nitro compounds. IV. Selective and sequential hydrogenation of nitroaromatics. J. Org. Chem. 1976, 41, 1200-1206.

(13) Toti, A.; Frediani, P.; Salvini, A.; Rosi, L.; Giolli, C. Hydrogenation of single and multiple $\mathrm{N}-\mathrm{N}$ or $\mathrm{N}-\mathrm{O}$ bonds by $\mathrm{Ru}(\mathrm{II})$ catalysts in homogeneous phase. J. Organomet. Chem. 2005, 690, 3641-3651.

(14) Deshmukh, A. A.; Prashar, A. K.; Kinage, A. K.; Kumar, R.; Meijboom, R. $\mathrm{Ru}(\mathrm{II})$ Phenanthroline Complex As Catalyst for Chemoselective Hydrogenation of Nitro-Aryls in a Green Process. Ind. Eng. Chem. Res. 2010, 49, 12180-12184.

(15) Deshpande, R. M.; Mahajan, A. N.; Diwakar, M. M.; Ozarde, P. S.; Chaudhari, R. V. Chemoselective hydrogenation of substituted nitroaromatics using novel water-soluble iron complex catalysts. J. Org. Chem. 2004, 69, 4835-4838.

(16) Wienhofer, G.; Baseda-Kruger, M.; Ziebart, C.; Westerhaus, F. A.; Baumann, W.; Jackstell, R.; Junge, K.; Beller, M. Hydrogenation of nitroarenes using defined iron-phosphine catalysts. Chem. Commun. 2013, 49, 9089-9091.

(17) (a) Zubar, V.; Sklyaruk, J.; Brzozowska, A.; Rueping, M. Chemoselective Hydrogenation of Alkynes to (Z)-Alkenes Using an Air-Stable Base Metal Catalyst. Org. Lett. 2020, 22, 5423-5428. (b) Azofra, L. M.; Tran, M. A.; Zubar, V.; Cavallo, L.; Rueping, M.; El-Sepelgy, O. Conversion of racemic alcohols to optically pureamine precursors enabled by catalyst dynamickinetic resolution: experiment and computation. Chem. Commun. 2020, 56, 9094-9097. (c) Sklyaruk, J.; Zubar, V.; Borghs, J. C.; Rueping, M. Sustainable ManganeseCatalyzed Solvent-Free Synthesis of Pyrroles from 1,4-Diols and Primary Amines. Org. Lett. 2020, 22, 6067-6071. (d) Borghs, J. C.; Zubar, V.; Azofra, L. M.; Sklyaruk, J.; Rueping, M. ManganeseCatalyzed Regioselective Dehydrogenative C- versus N-Alkylation Enabled by a Solvent Switch: Experiment and Computation. Org. Lett. 2020, 22, 4222-4227. (e) Zubar, V.; Borghs, J. C.; Rueping, M. Hydrogenation or Dehydrogenation of $\mathrm{N}$-Containing Heterocycles Catalyzed by a Single Manganese Complex. Org. Lett. 2020, 22, 3974-3978. (f) Brzozowska, A.; Zubar, V.; Ganardi, R.-C.; Rueping, M. Chemoselective Hydroboration of Propargylic Alcohols and Amines Using a Manganese(II) Catalyst. Org. Lett. 2020, 22, 3765-3769. (g) Borghs, J. C.; Tran, M. A.; Sklyaruk, J.; Rueping, M.; El-Sepelgy. Sustainable Alkylation of Nitriles with Alcohols by Manganese Catalysis. J. Org. Chem. 2019, 84, 7927-7935. (h) Borghs, J. C.; Azofra, L. M.; Biberger, T.; Linnenberg, O.; Cavallo, L.; Rueping, M.; El-Sepelgy, O. Manganese-Catalyzed Multicomponent Synthesis of Pyrroles through Acceptorless Dehydrogenation Hydrogen Autotransfer Catalysis: Experiment and Computation. ChemSusChem 2019, 12, 3083-3088. (i) Matador, E.; Brzozowska, A.; ElSepelgy, O.; Rueping, M. C-Alkylation of Secondary Alcohols by Primary Alcohols through Manganese-Catalyzed Double Hydrogen Autotransfer. ChemSusChem 2019, 12, 3099-3102. (j) Borghs, J. C.; Lebedev, Y.; Rueping, M.; El-Sepelgy, O. Sustainable ManganeseCatalyzed Solvent-Free Synthesis of Pyrroles from 1,4-Diols and Primary Amines. Org. Lett. 2019, 21, 70-74. (k) Sklyaruk, J.; Borghs, J.; El-Sepelgy, O.; Rueping, M. Catalytic $\mathrm{C}_{1}$-Alkylation with Methanol and Isotope-Labeled Methanol. Angew. Chem., Int. Ed. 2019, 58, 775779. (1) Jang, Y. K.; Krückel, T.; Rueping, M.; El-Sepelgy, O. Sustainable Alkylation of Unactivated Esters and Amides with Alcohols Enabled by Manganese Catalysis. Org. Lett. 2018, 20, 7779-7783. (m) Brzozowska, A.; Azofra, L. M.; Zubar, V.; Atodiresei, I.; Cavallo, L.; Rueping, M.; El-sepelgy, O. Highly Chemo- and Stereoselective Transfer Semihydrogenation of Alkynes Catalyzed by a Stable, Well-Defined Manganese(II) Complex. ACS Catal. 2018, 8, 4103-4109.
(18) Bruneau-Voisine, A.; Wang, D.; Roisnel, T.; Darcel, C.; Sortais, J.-B. Hydrogenation of ketones with a manganese PN $3 \mathrm{P}$ pincer precatalyst. Catal. Commun. 2017, 92, 1-4.

(19) Das, U. K.; Kumar, A.; Ben-David, Y.; Iron, M. A.; Milstein, D. Manganese Catalyzed Hydrogenation of Carbamates and Urea Derivatives. J. Am. Chem. Soc. 2019, 141, 12962-12966.

(20) Elangovan, S.; Garbe, M.; Jiao, H.; Spannenberg, A.; Junge, K.; Beller, M. Hydrogenation of Esters to Alcohols Catalyzed by Defined Manganese Pincer Complexes. Angew. Chem., Int. Ed. 2016, 55, 15364-15368.

(21) Elangovan, S.; Topf, C.; Fischer, S.; Jiao, H.; Spannenberg, A.; Baumann, W.; Ludwig, R.; Junge, K.; Beller, M. Selective Catalytic Hydrogenations of Nitriles, Ketones, and Aldehydes by Well-Defined Manganese Pincer Complexes. J. Am. Chem. Soc. 2016, 138, 88098814.

(22) Garbe, M.; Junge, K.; Walker, S.; Wei, Z.; Jiao, H.; Spannenberg, A.; Bachmann, S.; Scalone, M.; Beller, M. Manganese(I)-Catalyzed Enantioselective Hydrogenation of Ketones Using a Defined Chiral PNP Pincer Ligand. Angew. Chem., Int. Ed. 2017, 56, 11237-11241.

(23) Glatz, M.; Stoger, B.; Himmelbauer, D.; Veiros, L. F.; Kirchner, K. Chemoselective Hydrogenation of Aldehydes under Mild, BaseFree Conditions: Manganese Outperforms Rhenium. ACS Catal. 2018, 8, 4009-4016.

(24) Kaithal, A.; Hölscher, M.; Leitner, W. Catalytic Hydrogenation of Cyclic Carbonates using Manganese Complexes. Angew. Chem., Int. Ed. 2018, 57, 13449-13453.

(25) Kallmeier, F.; Irrgang, T.; Dietel, T.; Kempe, R. Highly Active and Selective Manganese $\mathrm{C}=\mathrm{O}$ Bond Hydrogenation Catalysts: The Importance of the Multidentate Ligand, the Ancillary Ligands, and the Oxidation State. Angew. Chem., Int. Ed. 2016, 55, 11806-11809.

(26) Kumar, A.; Janes, T.; Espinosa-Jalapa, N. A.; Milstein, D. Manganese Catalyzed Hydrogenation of Organic Carbonates to Methanol and Alcohols. Angew. Chem., Int. Ed. 2018, 57, 1207612080

(27) Papa, V.; Cabrero-Antonino, J. R.; Alberico, E.; Spanneberg, A.; Junge, K.; Junge, H.; Beller, M. Efficient and selective hydrogenation of amides to alcohols and amines using a well-defined manganesePNN pincer complex. Chem. Sci. 2017, 8, 3576-3585.

(28) Widegren, M. B.; Harkness, G. J.; Slawin, A. M. Z.; Cordes, D. B.; Clarke, M. L. A Highly Active Manganese Catalyst for Enantioselective Ketone and Ester Hydrogenation. Angew. Chem., Int. Ed. 2017, 56, 5825-5828.

(29) Zou, Y. Q.; Chakraborty, S.; Nerush, A.; Oren, D.; DiskinPosner, Y.; Ben-David, Y.; Milstein, D. Highly Selective, Efficient Deoxygenative Hydrogenation of Amides Catalyzed by a Manganese Pincer Complex via Metal-Ligand Cooperation. ACS Catal. 2018, 8, 8014-8019.

(30) Zubar, V.; Lebedev, Y.; Azofra, L. M.; Cavallo, L.; El-Sepelgy, O.; Rueping, M. Hydrogenation of $\mathrm{CO} 2$-Derived Carbonates and Polycarbonates to Methanol and Diols by Metal-Ligand Cooperative Manganese Catalysis. Angew. Chem., Int. Ed. 2018, 57, 13439-13443.

(31) For recent reviews on Mn catalysis, see: (a) Zell, T.; Langer, R. From Ruthenium to Iron and Manganese-A Mechanistic View on Challenges and Design Principles of Base-Metal Hydrogenation Catalysts. ChemCatChem 2018, 10, 1930-1940. (b) Mukherjee, A.; Milstein, D. Homogeneous Catalysis by Cobalt and Manganese Pincer Complexes. ACS Catal. 2018, 8, 11435-11469. (c) Kallmeier, F.; Kempe, R. Manganese Complexes for (De)Hydrogenation Catalysis: A Comparison to Cobalt and Iron Catalysts. Angew. Chem., Int. Ed. 2018, 57, 46-60. (d) Gorgas, N.; Kirchner, K. Isoelectronic Manganese and Iron Hydrogenation/Dehydrogenation Catalysts: Similarities and Divergences. Acc. Chem. Res. 2018, 51, 1558-1569. (e) Filonenko, G. A.; van Putten, R.; Hensen, E. J. M.; Pidko, E. A. Catalytic (de)hydrogenation promoted by non-precious metals - $\mathrm{Co}, \mathrm{Fe}$ and $\mathrm{Mn}$ : recent advances in an emerging field. Chem. Soc. Rev. 2018, 47, 1459-1483. (f) Maji, B.; Barman, M. K. Recent Developments of Manganese Complexes for Catalytic Hydrogenation and Dehydrogenation Reactions. Synthesis 2017, 49, 3377-3393. 
(g) Garbe, M.; Junge, K.; Beller, M. Homogeneous Catalysis by Manganese-Based Pincer Complexes. Eur. J. Org. Chem. 2017, 2017, 4344-4362. (h) Valyaev, D. A.; Lavigne, G.; Lugan, N. Manganese organometallic compounds in homogeneous catalysis: Past, present, and prospects. Coord. Chem. Rev. 2016, 308, 191-235. (i) Carney, J. R.; Dillon, B. R.; Thomas, S. P. Recent Advances of Manganese Catalysis for Organic Synthesis. Eur. J. Org. Chem. 2016, 2016, 39123929. (j) Liu, W.; Ackermann, L. Manganese-Catalyzed C-H Activation. ACS Catal. 2016, 6, 3743-3752. (k) Wang, C. Manganese-Mediated $\mathrm{C}-\mathrm{C}$ Bond Formation via $\mathrm{C}-\mathrm{H}$ Activation: From Stoichiometry to Catalysis. Synlett 2013, 24, 1606-1613.

(32) Zupancic, B. New Process for the Synthesis of 1-(2-((2,4Dimethylphenyl)thio)phenyl)piperazine. WO 2014191548 A1, 2014.

(33) For reviews on metal-ligand cooperative catalysis, see: (a) Khusnutdinova, R.; Milstein, D. Metal-Ligand Cooperation. Angew. Chem., Int. Ed. 2015, 54, 12236-12273. (b) Luca, O. R.; Crabtree, R. H. Redox-active ligands in catalysis. Chem. Soc. Rev. 2013, 42, 1440-1459. (c) Lyaskovskyy, V.; de Bruin, B. Redox NonInnocent Ligands: Versatile New Tools to Control Catalytic Reactions. ACS Catal. 2012, 2, 270-279.

(34) Karwa, S. L.; Rajadhyaksha, R. A. Selective catalytic hydrogenation of nitrobenzene to hydrazobenzene. Ind. Eng. Chem. Res. 1988, 27, 21-24.

(35) (a) Hu, L.; Cao, X.; Shi, L.; Qi, F.; Guo, Z.; Lu, J.; Gu, H. A highly active nano-palladium catalyst for the preparation of aromatic azos under mild conditions. Org. Lett. 2011, 13, 5640-5643. (b) Sahoo, M. K.; Saravanakumar, K.; Jaiswal, G.; Balaraman, E. Photocatalysis Enabling Acceptorless Dehydrogenation of Diaryl Hydrazines at Room Temperature. ACS Catal. 2018, 8, 7727-7733.

(36) Hu, L.; Cao, X.; Chen, L.; Zheng, J.; Lu, J.; Sun, X.; Gu, H. Highly efficient synthesis of aromatic azos catalyzed by unsupported ultra-thin Pt nanowires. Chem. Commun. 2012, 48, 3445-3447.

(37) Toti, A.; Frediani, P.; Salvini, A.; Rosi, L.; Giolli, C. Hydrogenation of single and multiple $\mathrm{N}-\mathrm{N}$ or $\mathrm{N}-\mathrm{O}$ bonds by $\mathrm{Ru}$ (II) catalysts in homogeneous phase. J. Organomet. Chem. 2005, 690, 3641-3651. 